\title{
Neuromodulatory Neurotransmitters Influence LTP-Like Plasticity in Human Cortex: A Pharmaco-TMS Study
}

\author{
Alexei Korchounov ${ }^{1,2}$ and Ulf Ziemann*,1 \\ 'Department of Neurology, Goethe-University Frankfurt, Frankfurt, Germany
}

\begin{abstract}
Long-term potentiation (LTP) of synaptic efficacy is considered a fundamental mechanism of learning and memory. At the cellular level a large body of evidence demonstrated that the major neuromodulatory neurotransmitters dopamine (DA), norepinephrine (NE), and acetylcholine (ACh) influence LTP magnitude. Noninvasive brain stimulation protocols provide the opportunity to study LTP-like plasticity at the systems level of human cortex. Here we applied paired associative stimulation (PAS) to induce LTP-like plasticity in the primary motor cortex of eight healthy subjects. In a double-blind, randomized, placebo-controlled, crossover design, the acute effects of a single oral dose of the neuromodulatory drugs cabergoline (DA agonist), haloperidol (DA antagonist), methylphenidate (indirect NE agonist), prazosine (NE antagonist), tacrine (ACh agonist), and biperiden (ACh antagonist) on PAS-induced LTP-like plasticity were examined. The antagonists haloperidol, prazosine, and biperiden depressed significantly the PAS-induced LTP-like plasticity observed under placebo, whereas the agonists cabergoline, methylphenidate, and tacrine had no effect. Findings demonstrate that antagonists in major neuromodulatory neurotransmitter systems suppress LTP-like plasticity at the systems level of human cortex, in accord with evidence of their modulating action of LTP at the cellular level. This provides further supportive evidence for the known detrimental effects of these drugs on LTP-dependent mechanisms such as learning and memory.

Neuropsychopharmacology (201 I) 36, 1894-1902; doi: I0.1038/npp.20I I.75; published online 4 May 20I I
\end{abstract}

Keywords: LTP-like plasticity; human motor cortex; transcranial magnetic stimulation; dopamine; norepinephrine; acetylcholine

\section{INTRODUCTION}

Long-term potentiation (LTP) of synaptic efficacy in neocortical networks is considered a fundamental mechanism of learning and memory formation (Asanuma and Pavlides, 1997; Sanes and Donoghue, 2000; Lynch, 2004; Feldman, 2009). At the cellular level, the neuromodulatory neurotransmitters dopamine (DA), norepinephrine (NE), and acetylcholine (ACh) can significantly influence the expression of LTP (Gu, 2002, 2003; Otani et al, 2003). Recently developed noninvasive brain stimulation protocols provide the opportunity to study LTP-like plasticity at the systems level of human cortex (Cooke and Bliss, 2006; Thickbroom, 2007; Ziemann et al, 2008; Müller-Dahlhaus et al, 2010).

With respect to the physiological properties, paired associative stimulation (PAS) is the currently best investigated of these protocols (Ziemann et al, 2008; Müller-Dahlhaus et al, 2010). Electrical peripheral nerve

*Correspondence: Professor $\cup$ Ziemann, Department of Neurology, Goethe-University, Schleusenweg 2-16, D-60528 Frankfurt am Main, Germany, Tel: + 4969 630I 5739, Fax: + 49696301 4498,

E-mail: u.ziemann@em.uni-frankfurt.de

${ }^{2}$ Current address: Marienhospital, Kevelaer, Germany

Received 16 February 2011; revised 28 March 2011; accepted 29

March 201। stimulation is repeatedly paired with transcranial magnetic stimulation (TMS) of the contralateral motor cortex. If the interstimulus interval is adjusted so that arrival of the afferent stimulus in motor cortex coincides with or slightly precedes TMS, then this typically leads to long-term increase of motor cortical excitability as measured by motor evoked potential (MEP) amplitude. The duration of MEP increase is $30-60$ min minimum but reversible within $24 \mathrm{~h}$ (Stefan et al, 2000). The MEP increase is dose dependent, that is, its magnitude and duration scales with the number of stimulus pairs (Nitsche et al, 2007). It saturates at $\sim 160-170 \%$ (Stefan et al, 2004; Nitsche et al, 2007). The site of MEP increase is in the motor cortex because motor responses elicited by direct electrical stimulation of the corticospinal tract do not change (Stefan et al, 2000), whereas epidural recordings of the descending corticospinal volley at the level of the cervical spinal cord show a significant increase (Di Lazzaro et al, 2009). Finally, pharmacological blockade of $N$-methyl-D-aspartate receptors (NMDARs) prevents the PAS-induced MEP increase (Stefan et al, 2002). In summary, these findings provide convergent evidence that the PAS-induced long-term increase in MEP amplitude can be taken as a model of LTP-like plasticity at the systems level of human motor cortex (Cooke and Bliss, 2006; Ziemann et al, 2008; MüllerDahlhaus et al, 2010). This is supported further by the 
significant interactions of PAS with LTP-dependent processes such as motor learning (Ziemann et al, 2004; Stefan et al, 2006; Rosenkranz et al, 2007; Jung and Ziemann, 2009; Kang et al, 2011).

Pharmacological modulation of PAS-induced LTP-like plasticity is a relatively little explored field and the available data have not always been consistent. In the dopaminergic system, levodopa enhances its magnitude and duration (Kuo et al, 2008) but no longer when D2 receptors are blocked by sulpiride (Nitsche et al, 2009). On the other hand, the D2 receptor agonist ropinirole decreases PASinduced LTP-like plasticity dose dependently in an inverted U-shaped manner (Monte-Silva et al, 2009). In the cholinergic system, the cholinesterase inhibitor rivastigmine strongly increases magnitude and duration of PASinduced LTP-like plasticity (Kuo et al, 2007), whereas nicotine results in nonsignificant prolongation but no change in magnitude (Thirugnanasambandam et al, 2011). Studies in the noradrenergic system have not been done. Here we explored systematically the effects of neuromodulatory drugs (NMDs), that is, agonists and antagonists in all three major neuromodulatory neurotransmitter systems (DA, NE, and ACh), in a double-blind, randomized, placebo-controlled crossover design in healthy subjects. We expected significant modulating effects on PAS-induced LTP-like plasticity. These findings are pertinent to the setting of clinical neurorehabilitation, where NMDs may have detrimental or beneficial effects on the long-term outcome of sensorimotor function in stroke patients (Goldstein, 1995; Ziemann et al, 2006).

\section{SUBJECTS AND METHODS}

\section{Subjects}

A total of 24 right-handed (Oldfield, 1971) healthy, drugnaive subjects (age range 18-32 years; 11 women) were screened for resting motor threshold (RMT) of $\leqslant 50 \%$ of maximum stimulator output, and for PAS-induced LTP-like increase of MEP amplitude $\geqslant 1.2$ (ratio of MEP post-PAS/ pre-PAS) using a previously established PAS protocol (Stefan et al, 2000, 2002). LTP-like plasticity is highly variable between subjects (Müller-Dahlhaus et al, 2008; Ridding and Ziemann, 2010), but RMT $\leqslant 50 \%$ is a quick indicator for a likely 'PAS responder' (Müller-Dahlhaus et al, 2008). Like in other studies (Heidegger et al, 2010), a minimum amount of LTP-like plasticity of 1.2 was required because the primary aim of this study was test drug modulation of LTP-like plasticity. In all, 8 subjects (age range 19-26 years; 3 women) met the inclusion criteria and were enrolled into the study. All subjects gave written informed consent before participation. The study was approved by the ethics committee of the Goethe-University Hospital of Frankfurt and conforms to the latest version of the Declaration of Helsinki Principles.

\section{Electromyography (EMG)}

Surface EMG was recorded from the right abductor pollicis brevis (APB), using $\mathrm{Ag}-\mathrm{AgCl}$ cup electrodes in a bellytendon montage. The EMG raw signal was amplified and filtered $(0.02-2 \mathrm{kHz}$; Counterpoint Mk2 electromyograph;
Dantec, Skovlunde, Denmark), digitized (analog-digital rate, $5 \mathrm{kHz}$; CED Micro 1401; Cambridge Electronic Design, Cambridge, UK), and fed into a laboratory computer for online visual display and offline analysis. All recordings were obtained during muscle rest, which was monitored audio-visually using high-gain EMG $(50 \mu \mathrm{V} /$ division $)$.

\section{Transcranial Magnetic Stimulation}

Focal TMS was delivered through a figure-of-eight coil (diameter of each wing, $70 \mathrm{~mm}$ ) connected to a Magstim 200 magnetic stimulator with a monophasic current waveform (The Magstim Company, Carmarthenshire, Wales, UK). The coil was held tangential to the scalp with the handle pointing backwards and $45^{\circ}$ away from the midline so that the current induced in the brain ran from lateral-posterior to medial-anterior. This is the optimal orientation for transsynaptic activation of the corticospinal system (Di Lazzaro et al, 2008). The coil was held over the hand area of the left primary motor cortex (M1), defined as the optimal site for eliciting MEP in the right APB. This site was marked on the scalp with a felt-tip pen to assure a stable coil placement throughout the experiment. The RMT was determined as the minimum stimulus intensity that elicited a small MEP of $\geqslant 50 \mu \mathrm{V}$ in at least 5 out of consecutive 10 trials in the voluntarily relaxed right APB (Rossini et al, 1999).

\section{Induction of LTP-Like Plasticity by PAS}

PAS consisted of 90 stimulus pairs delivered over a period of $30 \mathrm{~min}$ at a rate of $0.05 \mathrm{~Hz}$ according to an established protocol (Stefan et al, 2000, 2002). Bipolar electrical stimulation of the right median nerve at the wrist (cathode proximal, constant-current square pulses of $1 \mathrm{~ms}$ duration, intensity of three times the perceptual sensory threshold) preceded TMS of the hand area of the left M1 by the individually determined latency of the median nerve somatosensory evoked early cortical potential (N20) plus $2 \mathrm{~ms}$. This interstimulus interval resulted in previous studies in consistent and reproducible LTP-like plasticity, that is, a long-lasting (>30 min) on average 1.5-fold increase in MEP amplitude (Müller et al, 2007; Jung and Ziemann, 2009; Heidegger et al, 2010). The TMS intensity was adjusted to elicit on average peak-to-peak MEP amplitudes of $1 \mathrm{mV}\left(\mathrm{MEP}_{1 \mathrm{mV}}\right)$ when TMS was given alone.

\section{Attention Level}

The level of attention, a significant modulator of PAS effects (Stefan et al, 2004), was controlled by asking the subjects to watch the stimulated hand and count the total number of electrical stimuli applied to the right median nerve during PAS. In addition, immediately before PAS, subjects rated their level of sedation on an ordinal scale, with 0 meaning no, 1 mild, 2 moderate, and 3 strong sedation.

\section{Study Drugs}

The acute drug effects on PAS-induced LTP-like plasticity were assessed for a single oral dose of the six NMDs in Table 1 and placebo (PBO). The NMD doses were selected 
Table I Study Drugs

\begin{tabular}{|c|c|c|c|}
\hline Drug & Main mode(s) of action & Dose (mg) & Plasma peak (h) \\
\hline \multicolumn{4}{|l|}{ Placebo (PBO) } \\
\hline Cabergoline (CAB) & Dopamine (D2) receptor agonist & $2 \mathrm{mg}$ & $2(0.5-4)$ \\
\hline Haloperidol (HAL) & Dopamine (D2) receptor antagonist & $2.5 \mathrm{mg}$ & $2-6$ \\
\hline Methylphenidate (MPH) & Indirect NE (and DA) agonist & $40 \mathrm{mg}$ & 2 \\
\hline Prazosine (PRZ) & $\alpha \mid$-Adrenergic receptor antagonist (NE antagonist) & I mg & 2 \\
\hline
\end{tabular}

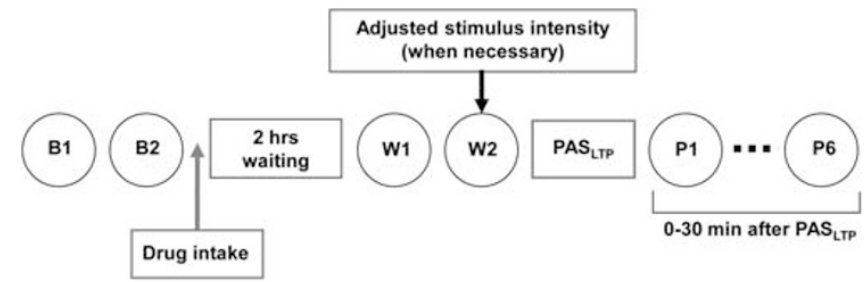

Figure I Time line of experimental procedures. The circles indicate blocks of 20 trials of MEP amplitude measurements (BI, B2: baseline before drug intake; WI, W2: 2 h after drug intake and immediately before PAS $S_{L T P}$; PI-P6: 0-30 min after PAS $L$ TP). At BI, B2, and W2, TMS intensity was adjusted to elicit MEP amplitudes of on average $1 \mathrm{mV}$. The ratio $\mathrm{WI} / \mathrm{B}$ informed on drug-induced change in MEP amplitude, whereas the ratio $\mathrm{PI}-\mathrm{P} 6 / \mathrm{W} 2$ informed on PAS-induced MEP change.

because they equal typical daily doses in clinical usage and/ or have already been demonstrated to alter significantly TMS measures of motor cortical excitability (for reviews, see Ziemann, 2004; Paulus et al, 2008; for specific references, see Table 1). The main modes of NMD action and their pharmacokinetics are also summarized in Table 1. Of note, all NMDs reach peak plasma levels approximately $2 \mathrm{~h}$ after oral intake.

\section{Study Design}

The six NMDs and PBO were given in separate sessions in a double-blind crossover design. The order of drugs was pseudo-randomized and counterbalanced across subjects. The intersession interval in a given subject was at least 1 week to exclude drug interference and carryover effects (Heidegger et al, 2010).

The time line of a single session is shown in Figure 1. All sessions started with two baseline blocks (B1, B2) of 20 MEP trials. The intertrial interval varied randomly between 8 and $12 \mathrm{~s}$ to minimize anticipation of the next trial. TMS intensity was adjusted to elicit $\mathrm{MEP}_{1 \mathrm{mv}}$. The study drug was taken immediately after B2. After a waiting period of $2 \mathrm{~h}$ (to reach NMD plasma peaks), another two blocks of 20 MEPs were recorded (W1 and $\mathrm{W} 2$ ). The measurements in $\mathrm{W} 1$ in comparison with baseline were used to assess NMD effects on corticospinal excitability. If the mean MEP amplitude in W1 deviated by $>30 \%$ from the mean of the MEP amplitudes in B1 and B2, TMS intensity during W2 was adjusted to re-establish MEP $_{1 \mathrm{mv}}$. This adjustment of TMS intensity was necessary in two subjects after prazosine (PRZ) and in two subjects after biperiden (BIP). This procedure assured that MEP amplitude was similar across drug conditions at the start of PAS for induction of LTP-like plasticity (Heidegger et al, 2010). Then, PAS was applied as described above. MEP amplitude after PAS was measured in six blocks (P1-P6), covering the first $30 \mathrm{~min}$ after PAS in steps of $5 \mathrm{~min}$. Each block consisted of 20 trials using the same stimulus intensity as in W2.

\section{Statistics}

All MEP data were checked for normal distribution using the Kolmogorov-Smirnov test. As normal distribution was confirmed throughout, parametric statistics (analysis of variance, ANOVA) were applied.

\section{Motor Cortical Excitability Before Drug Intake}

MEP amplitudes were averaged over the baseline time points B1 and B2. Baseline MEP amplitudes were compared between drugs (between-subject effect, seven levels: six NMDs and PBO) using ANOVA.

\section{Drug Effects on Motor Cortical Excitability}

MEP amplitudes at time point W1 were normalized to B (average of B1 and B2). The effects of drug (between-subject effect, seven levels: six NMDs and PBO) on the MEP ratio $\mathrm{W} 1 \mathrm{~B}$ was assessed using ANOVA. Because there was a main effect of drug on the MEP ratio W1B (see Results), post hoc paired $t$-tests adjusted for multiple comparisons using Bonferroni's method were conducted to compare the single drug conditions with PBO. Another ANOVA was calculated on the MEP ratio W2/B to ensure that, after TMS intensity adjustment, drug (between-subject effect, seven levels: six NMDs and PBO) no longer had an effect on MEP amplitude.

\section{Drug Effects on PAS-Induced LTP-Like Plasticity}

The primary measure of PAS-induced LTP-like plasticity was the mean MEP amplitude obtained during P1-P6 normalized to the mean MEP amplitude at time point W2. The effects of drug on PAS-induced LTP-like plasticity were analyzed in a repeated-measures ANOVA (rmANOVA) with the within-subject effect of time (six levels: P1-P6) and the between-subject effect of drug (seven levels: six NMDs and $\mathrm{PBO}$ ). Because there was a main effect of DRUG (see Results), six post hoc pairwise comparisons of PAS-induced LTP-like plasticity under the single NMD vs $\mathrm{PBO}$ were performed 
using rmANOVAs with the within-subject effects of drug (two levels, NMD vs PBO) and time (six levels, P1-P6). Adjustment for multiple comparisons was applied using Bonferroni's method.

For all tests, significance was assumed if $P<0.05$. Data are reported as means \pm 1 SEM.

In addition, drug effects on PAS-induced LTP-like plasticity were evaluated by calculating effect size, using Cohen's $d$ (Cohen, 1988). Beyond statistical significance, Cohen's $d$ estimates the biological relevance of these effects. Absolute values of Cohen's $d<0.8$ indicate weak or moderate effect sizes, whereas Cohen's $d \geqslant 0.8$ indicates strong effect sizes.

\section{RESULTS}

In one subject, the cabergoline (CAB) session had to be terminated after recording of W2 due to nausea and vomiting. Otherwise, all subjects tolerated the experimental procedures well. One subject noted slight sedation (level 1 on the ordinal scale $0-3$ ) in the haloperidol (HAL) session and two subjects in the BIP session, whereas no sedation (level 0) was rated in all other sessions. All subjects were capable of maintaining full compliance with all requirements of the tasks.

\section{Motor Cortical Excitability Before Drug Intake}

The $\mathrm{MEP}_{1 \mathrm{mV}}$ amplitudes before drug intake (mean MEP amplitude of time points B1 and B2) were not different between drugs $\left(\mathrm{F}_{6,42}=1.57, P=0.18\right)$, and were always close to the targeted amplitude of $1 \mathrm{mV}$ : $\mathrm{PBO}$ $1.05 \pm 0.18 \mathrm{mV} ; \mathrm{CAB} 1.06 \pm 0.09 \mathrm{mV} ; \mathrm{HAL} 1.17 \pm 0.11 \mathrm{mV}$; methylphenidate (MPH) $1.06 \pm 0.12 \mathrm{mV}$; PRZ $1.07 \pm 0.09 \mathrm{mV}$; tacrine (TAC) $1.04 \pm 0.06 \mathrm{mV}$; BIP $1.07 \pm 0.09 \mathrm{mV}$.

\section{Drug Effects on Motor Cortical Excitability}

The effect of drug on MEP amplitude (W1 normalized to B) was significant $\left(\mathrm{F}_{6,42}=3.43, P=0.008\right)$. Post hoc paired $t$-tests showed that PRZ increased MEP amplitude when compared with PBO $(P=0.008)$, whereas other drugs had no significant effect (Figure 2a). After adjustment of TMS intensity, the effect of drug on MEP amplitude (W2 normalized to B) remained borderline significant
$\left(\mathrm{F}_{6,42}=2.34, \quad P=0.047\right)$, but the post hoc comparisons showed that the MEP ratio W2/B was no longer significantly different for any NMD compared with PBO (Figure $2 b$ ). This is an important nil finding because there were no differences in MEP amplitude immediately before PAS that could have accounted for the significant drug effects on PAS-induced LTP-like plasticity (see below).

\section{Drug Effects on PAS-Induced LTP-Like Plasticity}

In the PBO condition, PAS resulted in a significant LTP-like increase in MEP amplitude (MEPs averaged across time points P1-P6 normalized to MEP amplitude at time point W2; $1.71 \pm 0.05, P<0.001$, one-sample $t$-test; Figure 3 ).

The rmANOVA revealed a significant effect of drug on PAS-induced LTP-like plasticity $\left(\mathrm{F}_{6,36}=11.59, P=0.0004\right.$, Figure 3), whereas there were no significant effects of time $\left(\mathrm{F}_{5,30}=1.55, P=0.21\right)$ or of the interaction of drug and time $\left(\mathrm{F}_{30,180}=0.81, P=0.75\right)$. Post hoc pairwise comparisons of PAS effects of each NMD with $\mathrm{PBO}$ revealed that induction of LTP-like plasticity was significantly reduced after intake of HAL $(P<0.0001$; MEPs averaged across time points P1-P6 normalized to MEP amplitude at time point $\mathrm{W} 2, \quad 1.04 \pm 0.03), \quad \mathrm{PRZ} \quad\left(P<0.0001 ; \quad \mathrm{MEP}_{\mathrm{P} 1-\mathrm{P} 6} / \mathrm{MEP}_{\mathrm{W} 2}\right.$ $1.04 \pm 0.04), \quad$ and $\quad$ BIP $\quad\left(P=0.0007 ; \quad \mathrm{MEP}_{\mathrm{P} 1-\mathrm{P} 6} / \mathrm{MEP}_{\mathrm{W} 2}\right.$ $1.20 \pm 0.05$ ). All other pairwise comparisons with $\mathrm{PBO}$ were not significant $(P>0.1$, Figure 3$)$. One-sample $t$-tests revealed that significant LTP-like increases in MEP amplitude occurred for CAB $(P<0.001)$, MPH $(P<0.001)$, and TAC $(P=0.03)$, whereas this was not the case for HAL, PRZ, and BIP (all $P>0.05$, Figure 3 ).

Calculation of effect size using Cohen's $d$ for the pairwise comparisons of PAS effects $\left(\mathrm{MEP}_{\mathrm{P} 1-\mathrm{P} 6} / \mathrm{MEP}_{\mathrm{W} 2}\right)$ under the influence of each NMD $v s$ PBO revealed the following values: $\mathrm{CAB} v s$ PBO: $d=0.63$; HAL $v s$ PBO: $d=-2.63$; $\mathrm{MPH}$ vs PBO: $d=0.13$; PRZ vs PBO: $d=-2.49$; ТAC $v s$ PBO: $d=-0.59$; BIP vs $\mathrm{PBO}: \mathrm{d}=-1.72$. Only the suppressive effects of HAL, PRZ, and BIP reached values of $|d| \geqslant 0.8$, indicating strong effect sizes.

\section{DISCUSSION}

The key novel findings of this study are that antagonists of major neuromodulatory neurotransmitter systems (DA, NE,
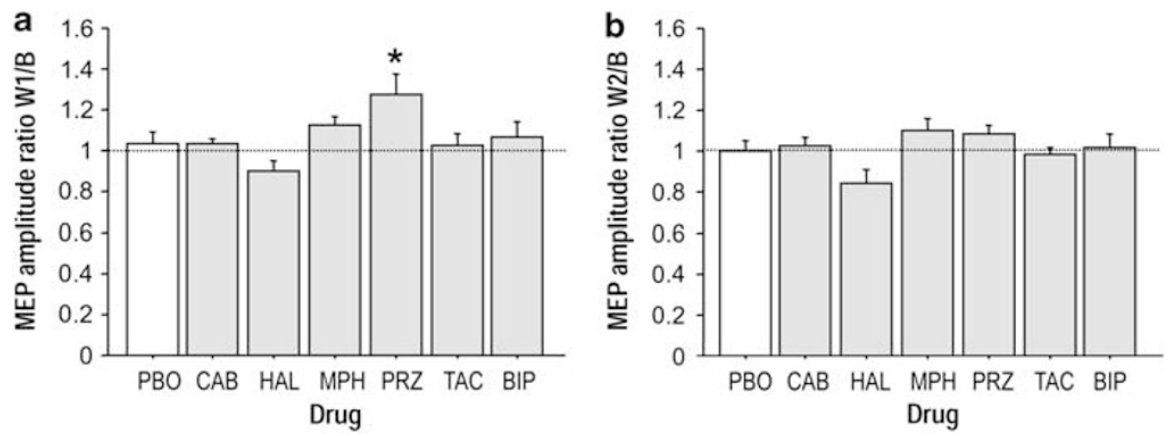

Figure 2 (a) MEP amplitude changes induced by the drugs ( $x$ axis, PBO: placebo; CAB: cabergoline; HAL: haloperidol; MPH: methylphenidate; PRZ: prazosine; TAC: tacrine; BIP: biperiden), expressed as ratio WI/B ( $y$ axis). B denotes the average of MEP recordings at baseline recordings BI and B2. (b) MEP amplitude changes after correction of TMS intensity expressed as ratio W2/B. The horizontal dotted lines indicate 1.0, that is, no change in MEP amplitude. All data are means $(n=8)+$ I SEM. $* p<0.05$. 


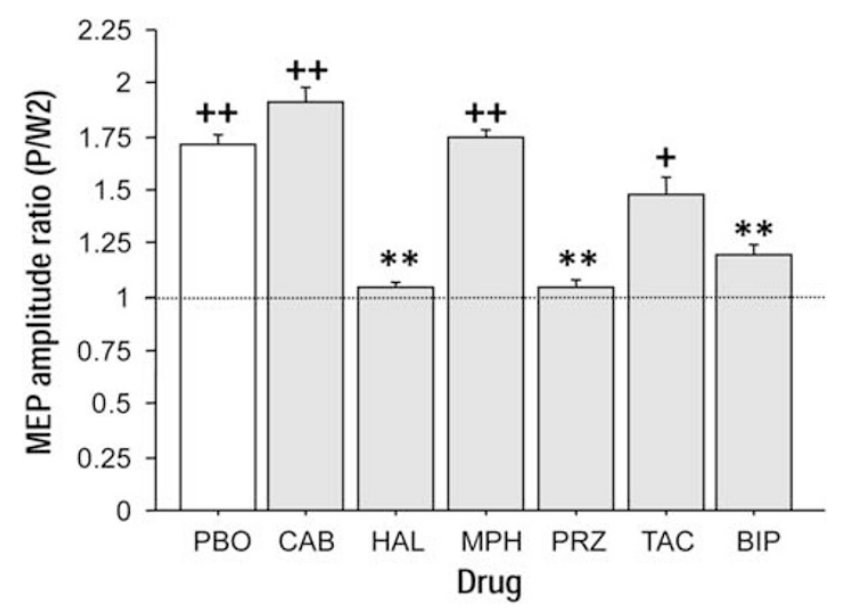

Figure 3 Effects of drugs ( $x$ axis, PBO: placebo; CAB: cabergoline; HAL: haloperidol; MPH: methylphenidate; PRZ: prazosine; TAC: tacrine; BIP: biperiden) on PAS-induced LTP-like plasticity expressed as MEP amplitude ratio $\mathrm{PI}-\mathrm{P} 6 / \mathrm{N} 2$ ( $y$ axis). The horizontal dotted line indicates 1.0, that is, no change in MEP amplitude. Note that PAS resulted in an LTP-like increase by $1.71 \pm 0.05$ in the PBO condition (white bar), whereas HAL, PRZ, and BIP led to significant depressions, and $\mathrm{CAB}, \mathrm{MPH}$, and TAC had no modulating effect when compared with PBO. All data are means ( $n=8$ for all drug conditions except $C A B$, where only 7 subjects completed the session) + I SEM. ${ }^{*} * *<0.00$ I (two-tailed paired t-test drug vs PBO); ${ }^{+} p<0.05$; ${ }^{+} p<0.00$ I (one-tailed $t$-tests indicating difference from I.0).

and $\mathrm{ACh}$ ) led to strong reductions of PAS-induced longterm increase in MEP amplitude, a model of LTP-like plasticity at the systems level of human cortex, whereas the effects of agonists in these neuromodulatory systems were nonsignificant. The single findings are discussed in the following paragraphs.

\section{Drug Effects on Motor Cortical Excitability}

Measurements of motor cortical excitability were restricted to $\mathrm{MEP}_{1 \mathrm{mV}}$ because the primary focus of this study was to examine modulating drug effects on PAS-induced LTP-like plasticity. The effects of agonists or antagonists of the major neuromodulatory neurotransmitter systems on MEP amplitude have not been studied widely in the past (for review, see Ziemann, 2004; Paulus et al, 2008). The effects were by and large weak and inconsistent, with the exception of $\mathrm{NE}$ agonists that produced a significant increase in MEP amplitude in most of the studies. The absence of major drug-induced $\mathrm{MEP}$ changes in this study $\left(\mathrm{MEP}_{\mathrm{W} 1 / \mathrm{B}}\right.$, Figure 2a) is in accord with the literature. This is an important nil finding because the drug effects on PASinduced LTP-like plasticity occurred in the absence of significant drug influence on MEP amplitude, the primary measure of LTP-like plasticity. The absence of relevant drug effects on corticomotor excitability per se and previous convergent evidence that PAS-induced LTP-like plasticity occurs at the site of the sensorimotor cortex (Stefan et al, 2000; Di Lazzaro et al, 2009) renders it very likely that the observed drug effects on PAS-induced plasticity occurred specifically at the level of sensorimotor cortex, even though the drugs were given systemically.

\section{Drug Effects on PAS-Induced LTP-Like Plasticity}

Dopaminergic, noradrenergic, and muscarinergic receptors are broadly represented in monkey and human M1 (Huntley et al, 1992; Geyer et al, 1996; Kötter et al, 2001), supporting a critical modulating role of these neuromodulatory neurotransmitter systems in motor function. Studies on the modulating effects of these neurotransmitter systems on LTP in M1 are, however, very scarce: the dopamine D1 receptor antagonist SCH02339 and the dopamine D2 receptor antagonist raclopride decrease LTP in rat M1 (Molina-Luna et al, 2009). Pharmacological blockade of muscarinic receptors by atropine also prevents the induction of LTP and rather favors the induction of long-term depression by the same stimulation protocol (Hess and Donoghue, 1999). Studies on a possible enhancement of LTP in M1 by neuromodulatory neurotransmitters are, to the best of our knowledge, not available.

We used here the PAS-induced LTP-like increase in MEP amplitude as a surrogate for LTP at the systems level of human motor cortex. We are fully aware that the evidence for this proposition is circumstantial but, given that the characteristics of the PAS-induced MEP increase are in all known detail consistent with LTP at the cellular level (see Introduction), this has become a widely accepted proposition even by cellular physiologists (Cooke and Bliss, 2006; Müller-Dahlhaus et al, 2010).

The significant drug effects on PAS-induced LTP-like plasticity were all suppressive and were caused by HAL, PRZ, and BIP, the antagonists of the examined neuromodulatory neurotransmitter systems ( $\mathrm{MEP}_{\mathrm{P} 1-\mathrm{P} 6 / \mathrm{W} 2}$, Figure 3$)$. Given the reported beneficial effects of agonists in these systems on motor learning and sensorimotor outcome after cerebral stroke (see below), one might have expected that $\mathrm{CAB}, \mathrm{MPH}$, and TAC had resulted in enhancing effects on PAS-induced LTP-like plasticity. However, a critical appraisal of the existing literature on pharmacological modulation of PAS-induced plasticity does not support this expectation: sulpiride, a selective dopamine D2 receptor antagonist, results in slight (nonsignificant) enhancement of PASinduced LTP-like plasticity (Nitsche et al, 2009), whereas ropinirole, a dopamine D2/D3 receptor agonist, dose dependently leads to a reduction (Monte-Silva et al, 2009). Furthermore, global dopamine receptor (ie, D1 and D2 receptor family) activation by levodopa, a precursor of dopamine, increases magnitude and duration of PASinduced LTP-like plasticity (Kuo et al, 2008), but only in the absence of dopamine D2 receptor blockade by sulpiride (Nitsche et al, 2009). These findings imply that a balanced co-activation of dopamine $\mathrm{D} 1$ and $\mathrm{D} 2$ receptors is necessary to enhance PAS-induced LTP-like plasticity. The absence of an enhancement of LTP-like plasticity by the selective dopamine $\mathrm{D} 2$ receptor agonist $\mathrm{CAB}$ in the present study is exquisitely consistent with those previous data.

The absence of an enhancement of PAS-induced LTP-like plasticity by TAC is at first sight surprising, given that a single oral dose of $3 \mathrm{mg}$ of the brain-selective cholinesterase inhibitor rivastigmine resulted in clear increase of magnitude and duration of this form of LTP-like plasticity (Kuo et al, 2007). Thus, $40 \mathrm{mg}$ of TAC and $3 \mathrm{mg}$ of rivastigmine are the typical daily starting doses and are equivalent to $25 \%$ of the recommended maximum daily dose in the 
treatment of Alzheimer's disease. The TAC/rivastigmine single oral dose ratio to result in 50\% inhibition of brain cholinesterase inhibition in rats is $\sim 5.6$ (Kosasa et al, 2000). As the TAC/rivastigmine dose ratio in the present $v s$ previous study (Kuo et al, 2007) is 13.3, it is highly unlikely that a too low dose of TAC explains the lack of its effect on PAS-induced LTP-like plasticity. One potentially important difference between the two drugs relates to their differential potency of decreasing electrically evoked ACh release through presynaptic muscarinic receptor-mediated autoinhibition. Although this is not observed to any measurable extent after acute exposure of human brain slices by rivastigmine, autoinhibition of ACh release by TAC occurs at brain concentrations that are likely reached by therapeutic doses (Jackisch et al, 2009). In the present experimental setting, the electrical peripheral nerve stimulation is associated with activation of central cholinergic afferents (Di Lazzaro et al, 2000; Tokimura et al, 2000). Therefore, it may be speculated that the PAS-evoked ACh release in sensorimotor cortex is autoinhibited in the TAC but not rivastigmine condition, and this could explain why rivastigmine but not TAC leads to enhancement of PASinduced LTP-like plasticity.

At low-to-moderate therapeutic dose, MPH increases predominantly the extracellular concentration of $\mathrm{NE}$ in the brain and only to a much lesser extent the concentration of DA (Kuczenski and Segal, 2001). MPH enhances LTP in rat hippocampus and this effect is mediated by $\beta$-adrenergic receptor activation (Dommett $e$ t al, 2008). MPH effects on neocortical LTP have never been examined, and the only study on NE modulation of neocortical LTP also demonstrated LTP enhancement via $\beta$-adrenergic receptor activation in rat visual cortex (Bröcher et al, 1992). Given the absence of any data in M1 to compare with, the reasons for the lacking effect of MPH on PAS-induced LTP-like plasticity in this study remain unclear. It is unlikely that the MPH dose was inappropriate because in previous studies the same dose resulted in significant change in motor cortical inhibition and facilitation (Ilic et al, 2003) and in enhancement of motor practice-dependent plasticity (Meintzschel and Ziemann, 2006). Clearly, further studies are needed to resolve the question of to which extent it is at all possible to enhance LTP in M1 by agonists in the NE system.

Another possible explanation for the absence of enhancing effects by the agonists $\mathrm{CAB}, \mathrm{TAC}$, and $\mathrm{MPH}$ is saturation of PAS-induced LTP-like plasticity in the PBO condition because all included subjects had been screened for a significant LTP-like response (see Subjects and Methods). As a consequence, the LTP-like increase in MEP amplitude of $1.71 \pm 0.05$ in the PBO condition is one of the largest reported in the literature (Wolters et al, 2003; Stefan et al, 2004; Ziemann et al, 2004; Nitsche et al, 2007). Therefore, one might argue that LTP-like plasticity was saturated already under PBO conditions and could not be enhanced any further. However, the amount of LTP-like plasticity under PBO conditions is not critical because it is the (unknown) individual synaptic modification range of the corticospinal system that matters. Although we cannot fully rule the possibility that saturation of LTP-like plasticity has occurred in the present experiments, this is unlikely for the following two reasons: (1) unpublished experiments of our group demonstrate that it is possible to build up LTP-like plasticity significantly beyond a factor of 1.7 by a second PAS $_{\text {LTP }}$ protocol if it follows the first PAS $S_{\text {LTP }}$ protocol by a delay of $\sim 30 \mathrm{~min}$ (Müller-Dahlhaus et al, unpublished data); and (2) in the present study, 7/8 subjects had at least one value of PAS-induced LTP-like plasticity in one of the drug conditions exceeding the one in the PBO condition, and this 'maximum LTP-like plasticity' $(1.96 \pm 0.07)$ was significantly larger than LTP-like plasticity in the PBO condition ( $P=0.04$, two-tailed paired $t$-test).

Still, the selection of 'PAS responders' and the relatively small sample size constitute limitations of this study, and it is possible that inclusion of subjects lacking a PAS-induced LTP-like response might have revealed enhancement of LTP-like plasticity by CAB, MPH, or TAC.

The following paragraph provides possible explanations for the observed suppressive effects of HAL, PRZ, and BIP on PAS-induced LTP-like plasticity. Given that the selective dopamine D2 receptor antagonist sulpiride slightly (nonsignificantly) increased LTP-like plasticity (Nitsche et al, 2009), the clearly suppressive effect of HAL can only be understood by taking into account important differences between HAL and sulpiride. The most parsimonious reason is the lower affinity of sulpiride $v s$ HAL at the dopamine D2 receptor (Matsubara et al, 1993). In addition, HAL inhibits the NMDAR containing NR1/2B subunits (Ilyin et al, 1996; Shim et al, 1999) but not the NMDAR containing NR1/2A. PAS-induced LTP-like plasticity is NMDAR dependent because it can be blocked by the noncompetitive NMDAR antagonist dextromethorphan (Stefan et al, 2002). Furthermore, NR1/2B rather than NR1/2A subunits containing NMDAR favor induction of LTP (Philpot et al, 2001). Another distinguishing feature is that HAL but not sulpiride has binding affinity to and blocks cortical ál-adrenergic receptors (Cohen and Lipinski, 1986; Patel et al, 2001). It is possible that blockade of á1-adrenergic receptors by HAL significantly contributed to its suppressive effect on PASinduced LTP-like plasticity as we demonstrated a similar suppressive effect by PRZ (cf., Figure 3), a selective antagonist of the $\alpha 1$-adrenergic receptor. This idea is supported by a linear regression analysis, which revealed a highly significant correlation between the suppressions of PAS-induced LTP-like plasticity (expressed as difference of $\mathrm{MEP}_{\mathrm{P} 1-\mathrm{P} 6 / \mathrm{W} 2}$ in the drug minus $\mathrm{PBO}$ conditions) caused by HAL $v$ s PRZ $(r=0.86, P=0.007)$. The molecular mechanisms involved in the suppression of LTP by $\alpha 1$-adrenergic receptor blockade are as of yet unknown.

The suppressive effect of BIP on PAS-induced LTP-like plasticity constitutes an independent effect because HAL does not bind to cortical muscarinic receptors (Richelson and Souder, 2000). BIP is a selective antagonist at the muscarinic M1 receptor (Bolden et al, 1992). Although the role of muscarinic M1 receptors in motor cortical LTP has not been investigated, enhanced muscarinic M1 neurotransmission facilitates several forms of NMDAR-dependent hippocampal and corticostriatal LTP, whereas blockade of muscarinic M1 receptors suppresses these forms of LTP (Calabresi et al, 1999; Ovsepian et al, 2004). The most likely mechanism for this modulation is colocalization of muscarinic M1 receptors with NMDAR and potentiation of NMDAR currents by muscarinic M1 receptor activation (Marino et al, 1998). 
In summary, our data suggest that LTP-like plasticity in human motor cortex is easily suppressed by antagonists of major neuromodulatory neurotransmitter systems, whereas enhancement of LTP-like plasticity is more difficult to obtain. This is in line with experiments in preparations of rat neocortex demonstrating that in contrast to LTP induction in primary somatosensory cortex, LTP induction in M1 does not show postsynaptic potential facilitation during repetitive burst stimulation in the LTP induction phase, and stable LTP can be obtained only under conditions of local disinhibition (Castro-Alamancos et al, 1995).

\section{Clinical Perspective}

The present findings bear on LTP-dependent processes such as motor learning in healthy subjects and motor re-learning in patients after central lesions. DA, NE, and ACh antagonists degrade practice-dependent plasticity in healthy subjects (Sawaki et al, 2002, 2003; Meintzschel and Ziemann, 2006), and retrospective studies strongly suggest that these NMDs are also detrimental in sensorimotor recovery after cerebral stroke (Goldstein et al, 1990; Goldstein, 1995). Conversely, DA, NE, and ACh agonists facilitate practice-dependent plasticity in healthy subjects (Bütefisch et al, 2002; Flöel et al, 2005a; Meintzschel and Ziemann, 2006) and may be beneficial in stroke rehabilitation (Crisostomo et al, 1988; Walker-Batson et al, 1995; Grade et al, 1998; Scheidtmann et al, 2001; Berthier et al, 2003; Flöel et al, 2005b; Zittel et al, 2007) although this evidence is not undisputed (for review, see Rösser and Flöel, 2008; Berends et al, 2009). The congruence of suppressive effects of NMDs on PASinduced LTP-like plasticity and practice-dependent plasticity suggests that PAS-induced LTP-like plasticity may serve as a biological marker for unfavorable drug effects on motor learning and recovery. On the other hand, the differences with respect to enhancing effects suggest that PAS-induced LTP-like plasticity and practicedependent plasticity are overlapping but not identical processes.

Finally, the present data are also pertinent to pathological conditions. Impaired PAS-induced LTP-like plasticity is typically observed in disorders associated with a dysfunctional dopaminergic system such as Parkinson's disease (Morgante et al, 2006; Ueki et al, 2006; Schwingenschuh et al, 2010) or schizophrenia (Frantseva et al, 2008), or a deficient central cholinergic system such as Alzheimer's disease (Battaglia et al, 2007), whereas exaggerated PASinduced LTP-like plasticity can be observed in states of increased endogenous central cholinergic tone such as dystonia (Quartarone et al, 2003, 2008; Weise et al, 2006; Schwingenschuh et al, 2010).

In conclusion, we have demonstrated that antagonists in major neuromodulatory neurotransmitter systems suppress LTP-like plasticity at the systems level of human cortex, in accord with evidence of their modulating action of LTP at the cellular level. This provides further supportive evidence for the known detrimental effects of these drugs on LTP-dependent mechanisms such as learning and memory.

\section{ACKNOWLEDGEMENTS}

We thank Dr Tihomir Ilic for help with some of the experiments.

\section{DISCLOSURE}

The authors declare that this study was supported by grant DFG ZI 542/4-1 (to UZ) from the German Research Foundation. UZ has received a grant from the Federal State of Hesse, and honoraria for editorial work from Brain Stimulation (Elsevier), and for scientific presentations from GlaxoSmithKline and Biogen Idec.

\section{REFERENCES}

Asanuma H, Pavlides C (1997). Neurobiological basis of motor learning in mammals. NeuroReport 8: i-vi.

Battaglia F, Wang HY, Ghilardi MF, Gashi E, Quartarone A, Friedman E et al (2007). Cortical plasticity in Alzheimer's disease in humans and rodents. Biol Psychiatry 62: 1405-1412.

Berends HI, Nijlant JM, Movig KL, Van Putten MJ, Jannink MJ, Ijzerman MJ (2009). The clinical use of drugs influencing neurotransmitters in the brain to promote motor recovery after stroke; a Cochrane systematic review. Eur J Phys Rehabil Med 45: 621-630.

Berthier ML, Pujol J, Gironell A, Kulisevsky J, Deus J, Hinojosa J et al (2003). Beneficial effect of donepezil on sensorimotor function after stroke. Am J Phys Med Rehabil 82: 725-729.

Bolden C, Cusack B, Richelson E (1992). Antagonism by antimuscarinic and neuroleptic compounds at the five cloned human muscarinic cholinergic receptors expressed in Chinese hamster ovary cells. J Pharmacol Exp Ther 260: 576-580.

Bröcher S, Artola A, Singer W (1992). Agonists of cholinergic and noradrenergic receptors facilitate synergistically the induction of long-term potentiation in slices of rat visual cortex. Brain Res 573: 27-36.

Bütefisch CM, Davis BC, Sawaki L, Waldvogel D, Classen J, Kopylev L et al (2002). Modulation of use-dependent plasticity by d-amphetamine. Ann Neurol 51: 59-68.

Calabresi P, Centonze D, Gubellini P, Bernardi G (1999). Activation of M1-like muscarinic receptors is required for the induction of corticostriatal LTP. Neuropharmacology 38: 323-326.

Castro-Alamancos MA, Donoghue JP, Connors BW (1995). Different forms of synaptic plasticity in somatosensory and motor areas of the neocortex. J Neurosci 15: 5324-5333.

Cohen BM, Lipinski JF (1986). In vivo potencies of antipsychotic drugs in blocking alpha 1 noradrenergic and dopamine D2 receptors: implications for drug mechanisms of action. Life Sci 39: 2571-2580.

Cohen J (1988). Statistical Power Analysis for the Behavioral Sciences. Lawrence Erlbaum Associates: Hillsdale.

Cooke SF, Bliss TV (2006). Plasticity in the human central nervous system. Brain 129: 1659-1673.

Crisostomo EA, Duncan PW, Propst M, Dawson DV, Davis JN (1988). Evidence that amphetamine with physical therapy promotes recovery of motor function in stroke patients. Ann Neurol 23: 94-97.

Di Lazzaro V, Dileone M, Pilato F, Profice P, Oliviero A, Mazzone P et al (2009). Associative motor cortex plasticity: direct evidence in humans. Cereb Cortex 19: 2326-2330.

Di Lazzaro V, Oliviero A, Profice P, Pennisi MA, Di Giovanni S, Zito $\mathrm{G}$ et al (2000). Muscarinic receptor blockade has differential effects on the excitability of intracortical circuits in human motor cortex. Exp Brain Res 135: 455-461. 
Di Lazzaro V, Ziemann U, Lemon RN (2008). State of the art: physiology of transcranial motor cortex stimulation. Brain Stimul 1: 345-362.

Dommett EJ, Henderson EL, Westwell MS, Greenfield SA (2008). Methylphenidate amplifies long-term plasticity in the hippocampus via noradrenergic mechanisms. Learn Mem 15: 580-586.

Feldman DE (2009). Synaptic mechanisms for plasticity in neocortex. Annu Rev Neurosci 32: 33-55.

Flöel A, Breitenstein C, Hummel F, Celnik P, Gingert C, Sawaki L et al (2005a). Dopaminergic influences on formation of a motor memory. Ann Neurol 58: 121-130.

Flöel A, Hummel F, Breitenstein C, Knecht S, Cohen LG (2005b). Dopaminergic effects on encoding of a motor memory in chronic stroke. Neurology 65: 472-474.

Frantseva MV, Fitzgerald PB, Chen R, Moller B, Daigle M, Daskalakis ZJ (2008). Evidence for impaired long-term potentiation in schizophrenia and its relationship to motor skill leaning. Cereb Cortex 18: 990-996.

Geyer S, Ledberg A, Schleicher A, Kinomura S, Schormann T, Burgel U et al (1996). Two different areas within the primary motor cortex of man. Nature 382: 805-807.

Goldstein LB (1995). Common drugs may influence motor recovery after stroke. The Sygen In Acute Stroke Study Investigators. Neurology 45: 865-871.

Goldstein LB, Matchar DB, Morgenlander JC, Davis JN (1990). Influence of drugs on the recovery of sensorimotor function after stroke. J Neuro Rehab 4: 137-144.

Grade C, Redford B, Chrostowski J, Toussaint L, Blackwell B (1998). Methylphenidate in early poststroke recovery: a doubleblind, placebo-controlled study. Arch Phys Med Rehabil 79: 1047-1050.

$\mathrm{Gu} \mathrm{Q}$ (2002). Neuromodulatory transmitter systems in the cortex and their role in cortical plasticity. Neuroscience 111: 815-835.

$\mathrm{Gu}$ Q (2003). Contribution of acetylcholine to visual cortex plasticity. Neurobiol Learn Mem 80: 291-301.

Heidegger T, Krakow K, Ziemann U (2010). Effects of antiepileptic drugs on associative LTP-like plasticity in human motor cortex. Eur J Neurosci 32: 1215-1222.

Hess G, Donoghue JP (1999). Facilitation of long-term potentiation in layer II/III horizontal connections of rat motor cortex following layer I stimulation: route of effect and cholinergic contributions. Exp Brain Res 127: 279-290.

Huntley GW, Morrison JH, Prikhozhan A, Sealfon SC (1992). Localization of multiple dopamine receptor subtype mRNAs in human and monkey motor cortex and striatum. Brain Res Mol Brain Res 15: 181-188.

Ilic TV, Korchounov A, Ziemann U (2003). Methylphenydate facilitates and disinhibits the motor cortex in intact humans. NeuroReport 14: 773-776.

Ilyin VI, Whittemore ER, Guastella J, Weber E, Woodward RM (1996). Subtype-selective inhibition of N-methyl-D-aspartate receptors by haloperidol. Mol Pharmacol 50: 1541-1550.

Jackisch R, Forster S, Kammerer M, Rothmaier AK, Ehret A, Zentner J et al (2009). Inhibitory potency of choline esterase inhibitors on acetylcholine release and choline esterase activity in fresh specimens of human and rat neocortex. J Alzheimers Dis 16: $635-647$.

Jung P, Ziemann U (2009). Homeostatic and non-homeostatic modulation of learning in human motor cortex. J Neurosci 29: 5597-5604.

Kang J-S, Terranova C, Hilker R, Quartarone A, Ziemann U (2011). Deficient homeostatic regulation of practice-dependent plasticity in writer's cramp. Cereb Cortex 21: 1203-1212.

Kosasa T, Kuriya Y, Matsui K, Yamanishi Y (2000). Inhibitory effect of orally administered donepezil hydrochloride (E2020), a novel treatment for Alzheimer's disease, on cholinesterase activity in rats. Eur J Pharmacol 389: 173-179.
Kötter R, Stephan KE, Palomero-Gallagher N, Geyer S, Schleicher A, Zilles K (2001). Multimodal characterisation of cortical areas by multivariate analyses of receptor binding and connectivity data. Anat Embryol (Berl) 204: 333-350.

Kuczenski R, Segal DS (2001). Locomotor effects of acute and repeated threshold doses of amphetamine and methylphenidate: relative roles of dopamine and norepinephrine. J Pharmacol Exp Ther 296: 876-883.

Kuo M-F, Grosch J, Fregni F, Paulus W, Nitsche MA (2007). Focusing effect of acetylcholine on neuroplasticity in the human motor cortex. J Neurosci 27: 14442-14447.

Kuo M-F, Paulus W, Nitsche MA (2008). Boosting focally-induced brain plasticity by dopamine. Cereb Cortex 18: 648-651.

Lynch MA (2004). Long-term potentiation and memory. Physiol Rev 84: 87-136.

Marino MJ, Rouse ST, Levey AI, Potter LT, Conn PJ (1998). Activation of the genetically defined $\mathrm{m} 1$ muscarinic receptor potentiates N-methyl-D-aspartate (NMDA) receptor currents in hippocampal pyramidal cells. Proc Natl Acad Sci USA 95: 11465-11470.

Matsubara S, Matsubara R, Kusumi I, Koyama T, Yamashita I (1993). Dopamine D1, D2 and serotonin2 receptor occupation by typical and atypical antipsychotic drugs in vivo. J Pharmacol Exp Ther 265: 498-508.

Meintzschel F, Ziemann U (2006). Modification of practicedependent plasticity in human motor cortex by neuromodulators. Cereb Cortex 16: 1106-1115.

Molina-Luna K, Pekanovic A, Rohrich S, Hertler B, SchubringGiese M, Rioult-Pedotti MS et al (2009). Dopamine in motor cortex is necessary for skill learning and synaptic plasticity. PLoS One 4: e7082.

Monte-Silva K, Kuo M-F, Thirugnanasambandam N, Liebetanz D, Paulus W, Nitsche M (2009). Dose-dependent inverted U-shaped effect of dopamine (D2-like) receptor activation on focal and nonfocal plasticity in humans. J Neurosci 29: 6124-6131.

Morgante F, Espay AJ, Gunraj C, Lang AE, Chen R (2006). Motor cortex plasticity in Parkinson's disease and levodopa-induced dyskinesias. Brain 129: 1059-1069.

Müller-Dahlhaus F, Ziemann U, Classen J (2010). Plasticity resembling spike-timing dependent synaptic plasticity: the evidence in human cortex. Front Syn Neurosci 2: 1-11.

Müller-Dahlhaus JF, Orekhov Y, Liu Y, Ziemann U (2008). Interindividual variability and age-dependency of motor cortical plasticity induced by paired associative stimulation. Exp Brain Res 187: 467-475.

Müller JFM, Orekhov Y, Liu Y, Ziemann U (2007). Homeostatic plasticity in human motor cortex demonstrated by two consecutive sessions of paired associative stimulation. Eur $J$ Neurosci 25: 3461-3468.

Nitsche MA, Kuo MF, Grosch J, Bergner C, Monte-Silva K, Paulus W (2009). D1-receptor impact on neuroplasticity in humans. J Neurosci 29: 2648-2653.

Nitsche MA, Roth A, Kuo M-F, Fischer AK, Liebetanz D, Lang N et al (2007). Timing-dependent modulation of associative plasticity by general network excitability in the human motor cortex. J Neurosci 27: 3807-3812.

Oldfield RC (1971). The assessment and analysis of handedness: the Edinburgh inventory. Neuropsychologia 9: 97-113.

Otani S, Daniel H, Roisin MP, Crepel F (2003). Dopaminergic modulation of long-term synaptic plasticity in rat prefrontal neurons. Cereb Cortex 13: 1251-1256.

Ovsepian SV, Anwyl R, Rowan MJ (2004). Endogenous acetylcholine lowers the threshold for long-term potentiation induction in the CA1 area through muscarinic receptor activation: in vivo study. Eur J Neurosci 20: 1267-1275.

Patel S, Fernandez-Garcia E, Hutson PH, Patel S (2001). An in vivo binding assay to determine central alpha(1)-adrenoceptor 
occupancy using [(3)H]prazosin. Brain Res Brain Res Protoc 8: 191-198.

Paulus W, Classen J, Cohen LG, Large CH, Di Lazzaro V, Nitsche M et al (2008). State of the art: pharmacologic effects on cortical excitability measures tested by transcranial magnetic stimulation. Brain Stimul 1: 151-163.

Philpot BD, Sekhar AK, Shouval HZ, Bear MF (2001). Visual experience and deprivation bidirectionally modify the composition and function of NMDA receptors in visual cortex. Neuron 29: $157-169$.

Quartarone A, Bagnato S, Rizzo V, Siebner HR, Dattola V, Scalfari A et al (2003). Abnormal associative plasticity of the human motor cortex in writer's cramp. Brain 126: 2586-2596.

Quartarone A, Morgante F, Sant'angelo A, Rizzo V, Bagnato S, Terranova C et al (2008). Abnormal plasticity of sensorimotor circuits extends beyond the affected body part in focal dystonia. J Neurol Neurosurg Psychiatry 79: 985-990.

Richelson E, Souder T (2000). Binding of antipsychotic drugs to human brain receptors focus on newer generation compounds. Life Sci 68: 29-39.

Ridding MC, Ziemann U (2010). Determinants of the induction of cortical plasticity by non-invasive brain stimulation inn healthy subjects. J Physiol 588: 2291-2304.

Rosenkranz K, Kacar A, Rothwell JC (2007). Differential modulation of motor cortical plasticity and excitability in early and late phases of human motor learning. J Neurosci 27: 12058-12066.

Rösser N, Flöel A (2008). Pharmacological enhancement of motor recovery in subacute and chronic stroke. NeuroRehabilitation 23: 95-103.

Rossini PM, Berardelli A, Deuschl G, Hallett M, Maertens de Noordhout AM, Paulus W et al (1999). Applications of magnetic cortical stimulation. Electroencephalogr Clin Neurophysiol Suppl 52: $171-185$.

Sanes JN, Donoghue JP (2000). Plasticity and primary motor cortex. Annu Rev Neurosci 23: 393-415.

Sawaki L, Boroojerdi B, Kaelin-Lang A, Burstein AH, Bütefisch $\mathrm{CM}$, Kopylev L et al (2002). Cholinergic influences on usedependent plasticity. J Neurophysiol 87: 166-171.

Sawaki L, Werhahn KJ, Barco R, Kopylev L, Cohen LG (2003). Effect of an alpha(1)-adrenergic blocker on plasticity elicited by motor training. Exp Brain Res 148: 504-508.

Scheidtmann K, Fries W, Muller F, Koenig E (2001). Effect of levodopa in combination with physiotherapy on functional motor recovery after stroke: a prospective, randomised, doubleblind study. Lancet 358: 787-790.

Schwingenschuh P, Ruge D, Edwards MJ, Terranova C, Katschnig $\mathrm{P}$, Carrillo F et al (2010). Distinguishing SWEDDs patients with asymmetric resting tremor from Parkinson's disease: a clinical and electrophysiological study. Mov Disord 25: 560-569.

Shim SS, Grant ER, Singh S, Gallagher MJ, Lynch DR (1999). Actions of butyrophenones and other antipsychotic agents at NMDA receptors: relationship with clinical effects and structural considerations. Neurochem Int 34: 167-175.
Stefan K, Kunesch E, Benecke R, Cohen LG, Classen J (2002). Mechanisms of enhancement of human motor cortex excitability induced by interventional paired associative stimulation. $J$ Physiol 543: 699-708.

Stefan K, Kunesch E, Cohen LG, Benecke R, Classen J (2000). Induction of plasticity in the human motor cortex by paired associative stimulation. Brain 123: 572-584.

Stefan K, Wycislo M, Classen J (2004). Modulation of associative human motor cortical plasticity by attention. J Neurophysiol 92: 66-72.

Stefan K, Wycislo M, Gentner R, Schramm A, Naumann M, Reiners $\mathrm{K}$ et al (2006). Temporary occlusion of associative motor cortical plasticity by prior dynamic motor training. Cereb Cortex 16: 376-385.

Thickbroom GW (2007). Transcranial magnetic stimulation and synaptic plasticity: experimental framework and human models. Exp Brain Res 180: 583-593.

Thirugnanasambandam N, Grundey J, Adam K, Drees A, Skwirba AC, Lang $\mathrm{N}$ et al (2011). Nicotinergic impact on focal and non-focal neuroplasticity induced by non-invasive brain stimulation in non-smoking humans. Neuropsychopharmacology 36: $879-886$.

Tokimura H, Di Lazzaro V, Tokimura Y, Oliviero A, Profice P, Insola A et al (2000). Short latency inhibition of human hand motor cortex by somatosensory input from the hand. J Physiol 523: 503-513.

Ueki Y, Mima T, Ali Kotb M, Sawada H, Saiki H, Ikeda A et al (2006). Altered plasticity of the human motor cortex in Parkinson's disease. Ann Neurol 59: 60-71.

Walker-Batson D, Smith P, Curtis S, Unwin H, Greenlee R (1995). Amphetamine paired with physical therapy accelerates motor recovery after stroke. Further evidence. Stroke 26: 2254-2259.

Weise D, Schramm A, Stefan K, Wolters A, Reiners K, Naumann M et al (2006). The two sides of associative plasticity in writer's cramp. Brain 129: 2709-2721.

Wolters A, Sandbrink F, Schlottmann A, Kunesch E, Stefan K, Cohen LG et al (2003). A temporally asymmetric Hebbian rule governing plasticity in the human motor cortex. J Neurophysiol 89: 2339-2345.

Ziemann U (2004). TMS and drugs. Clin Neurophysiol 115: $1717-1729$.

Ziemann U, Ilic TV, Pauli C, Meintzschel F, Ruge D (2004). Learning modifies subsequent induction of LTP-like and LTD-like plasticity in human motor cortex. $J$ Neurosci 24: 1666-1672.

Ziemann U, Meintzschel F, Korchounov A, Ilic TV (2006). Pharmacological modulation of plasticity in the human motor cortex. Neurorehabil Neural Repair 20: 243-251.

Ziemann U, Paulus W, Nitsche MA, Pascual-Leone A, Byblow WD, Berardelli A et al (2008). Consensus: motor cortex plasticity protocols. Brain Stimul 1: 164-182.

Zittel S, Weiller C, Liepert J (2007). Reboxetine improves motor function in chronic stroke: a pilot study. J Neurol 254: 197-201. 